REVISTA CHILENA DE LITERATURA

Abril 2008, Número 72, 255 - 259

\title{
NERUDA Y LOS ESTUDIOS LITERARIOS
}

\author{
Raúl Zurita \\ Universidad Diego Portales \\ zurita_123@yahoo.com
}

Hombre del sur, poeta chileno, americano del mundo es el título bajo el cual se reúnen las actas del Congreso Internacional del Centenario del Natalicio de Pablo Neruda, realizado en Santiago en julio del 2004. Publicado ahora por la Facultad de Filosofía y Humanidades de la Universidad de Chile y editado por Manuel Jofré, constituye una relevante muestra del estado actual de los estudios nerudianos e ilumina muchos de los subtextos, pliegues y debates que cruzan nuestra realidad. Es lo que se constata en los estudios señeros de Hernán Loyola, Alain Siscard, Jaime Concha, Michael Predmore, Leandro Urbina, Paula Miranda y muchos otros, al mismo tiempo que, en lo que podemos llamar su contracara, estas actas evidencian los límites y fisuras de un particular modo de abordar el hecho poético que se engloba bajo el rótulo de estudios literarios. No es un detalle menor: el desfase inevitable entre un poema y su crítica radica en que la poesía, y esta una de sus definiciones más luminosas e inquietantes, es la respuesta a preguntas que aún no se han formulado y que probablemente no se formulen nunca. El efecto que se registra es entonces la distancia que media entre la interrogación a la que se somete al poema y la incógnita, la x de la ecuación, a la cual ese poema efectivamente está respondiendo. Pero esto es también un hecho irreductible. Más que por sus logros, una época se caracteriza por lo que le está radicalmente vedado de concebir, por su impensable, y el territorio del poema tiene que ver más con ese impensable que con las zonas iluminadas de una sociedad o de un tiempo. Es lo que la astrofísica llama materia oscura, que constituye el $70 \%$ del universo y cuya mayor consistencia radica precisamente en que lo ignoramos absolutamente todo sobre ella. Siguiendo con la astrofísica, la poesía son los black holes, los hoyos negros del lenguaje, todas las leyes dejan de funcionar en sus cercanías.

Otra de las condiciones que se pasa por alto es que, desde la Teogonía de Hesiodo, la poesía no tiene nada que ver con la verdad. Las musas, al presentarse a Hesiodo en el comienzo del poema, de inmediato le dicen que ellas pueden decir muchas mentiras con apariencia de verdad y también decir la verdad cuando les plazca. Las consecuencias de 
esta sentencia en la historia serán enormes y marcarán la absoluta distancia entre poesía y religión, partiendo por el hecho básico de que, a diferencia de los textos dictados por la verdad, es decir por Dios, jamás en nombre de la poesía se podrá condenar a alguien al patíbulo, a la inquisición o a la hoguera. Es esa radical opacidad del hecho poético la que soslayan por lo general los estudios literarios. Tratándose de un poeta de las dimensiones de Pablo Neruda, esto se hace más evidente aún. Porque lo cierto es que de pronto parece que nada existiera fuera del pulso de algunas palabras, de ciertos versos y poemas que nos dan vueltas y vueltas en la cabeza igual que un latido que no termina. Podemos incluso llegar a sentir su presión punzándonos desde detrás de la frente, como si esos poemas quisieran hacernos entender que nosotros mismos no somos sino un pequeño episodio de algo escrito mucho antes de que fuese inventado lo humano. La sensación no es distinta a la que podemos experimentar mirando la inmensidad del mar o las cumbres de los Andes. Poemas como la Ilíada y la Odisea, el Mahabharata hindú o los grandes textos bíblicos nos hacen pensar en esas dimensiones. No importa el tiempo en que fueron escritas ni los siglos que generaciones ocuparon en escribirlas, obras así son tan plenas y sobrecogedoras que, como decíamos, más que a lo humano se asemejan a los grandes escenarios de la naturaleza. Es el caso de Pablo Neruda. Muchas veces su poesía parece exceder los límites de las creaciones individuales para acercarse a los grandes relatos míticos. Es particularmente lo que sucede con su poema “Alturas de Macchu Picchu” y con la imagen que emerge del Canto General.

Porque lo impresionante es que nada hay ni en un idioma ni en un ser humano que haga posible que los grandes poemas existan, y sin embargo ellos existen. Nada existía ni en el italiano ni en Dante que posibilitara que fuese escrita la Comedia, ni en el inglés ni en ese tal Shakespeare para que algo como los sonetos de Shakespeare se escribieran. Es el caso también de “Alturas de Macchu Picchu”. Esto toca un aspecto que ninguno de los trabajos de estas actas aborda, porque todos parten de un presupuesto común: que la relación entre poesía y lengua es transparente. Que la lengua en la que se escribe es el dato básico y por lo tanto se obvia, se da por establecida de una vez para siempre. En la época de la agonía del lenguaje, al menos del lenguaje tal como fue entendido desde Homero, y de la supremacía total del idioma de la publicidad, ese presupuesto ya no es sostenible y en el caso de la poesía latinoamericana es mucho menos sostenible aún. El asunto en sí no es complejo: se trata de que la historia de estos territorios es, y de un modo medular, central, la historia de la violencia ejercida por una lengua y las marcas futuras de esa violencia. Y no me estoy refiriendo a la violencia de quienes impusieron la lengua, esto es, los conquistadores, sino a la violencia de la lengua misma. De la lengua de la contrarreforma y de la conquista de América. Herederos de esa historia, nos ha tocado a nosotros también ser la memoria viva de su condena. Los hispanoparlantes de este continente hablamos un idioma que guarda de una u otra forma en cada palabra, en cada giro, en cada una de sus letras, la memoria de las condiciones en que ese idioma se impuso.

Es lo que está expresado en el poema “España aparta de mí este cáliz” del libro del mismo nombre de César Vallejo. Allí se dice que si España cae Cómo vais a bajar las gradas del alfabeto / hasta la letra en que nació la pena. Lo que se nos está afirmando 
es que en estas tierras el dolor es inextirpable porque él está incrustado en las partículas mismas del idioma impuesto. Es lo que el mismo Vallejo ha evidenciado en Trilce, donde cada poema es, literalmente, un cuerpo sacrificado. La alteración total de la sintaxis, los arcaísmos y neologismos, la furia de los signos de exclamación, de las palabras cortadas, de las mayúsculas, en fin, toda esa violencia permanente de cada palabra con la contigua, su enterramiento mutuo, sus chirridos, nos muestra que los textos de Trilce son en sí mismos cuerpos puestos en posición de perpetua agonía, carnes torturadas, miembros encepados. Pero quien habla en los poemas de Vallejo también habla en Altazor, y el entusiasmo de Vicente Huidobro por un idioma que ha de nacer de las ruinas de las lenguas muertas que hablamos, a las que se refiere en el Canto III, es el mismo padecimiento vallejiano, pero con un signo opuesto. Sombras entonces de una condena primigenia, Huidobro y Vallejo revelan desde los extremos de Trilce y de la pulverización del castellano en el Canto VII de Altazor, la misma condición trágica de un idioma y de una historia que no logra la paz con sus hablantes y que se ve, por eso mismo, obligada a inventar su propia geografía, sus toponimias, sus relieves, cristalizando una naturaleza paralela al mundo que será siempre, en la escritura de ambos, una representación de lo inacabado de la muerte. Eso también es, en síntesis, lo que Huidobro llamó “creacionismo”.

Sin embargo, ya el poema inaugural de Alonso de Ercilla denotaba esa carga, al concebir la naturaleza como una escenografía que la pasión de la conquista va levantando. Vendrá a ser precisamente con Neruda en "Alturas de Macchu Picchu” donde los conquistados, respondiéndole a La Araucana, apelarán a un nuevo sentido de las palabras. Lo que allí se abre es la apelación a un futuro liberado que solo será posible a partir de la reconciliación con el idioma impuesto. Macchu Picchu es así la promesa que la poesía hispanoamericana levanta de un mundo y de una significación nueva y su escritura constituye un hecho infinitamente más importante en la historia de la independencia de estas antiguas colonias que las batallas de Maipú y de Ayacucho.

Hay que escuchar entonces el despliegue de las palabras en este poema:

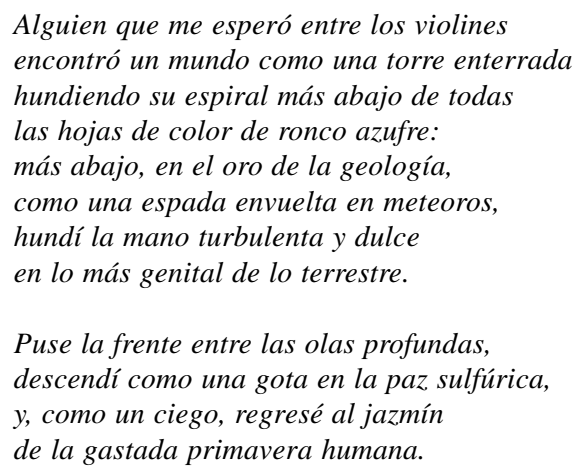

Puse la frente entre las olas profundas, descendí como una gota en la paz sulfúrica, y, como un ciego, regresé al jazmín de la gastada primavera humana.

Hay que oírlo, es semejante a un río que trajera arrastrando un montón de piedras hasta que en un momento las suelta de golpe, arrojándolas de tal forma que cada piedra cae 
exactamente en el lugar que le estaba destinada desde siempre. En el único y perfecto lugar. Esa disposición de las palabras supone haber alcanzado una reconciliación total con la lengua que hablamos y hace que esa cifra que desde el 23 de septiembre de 1973 se conoce por Neruda, más que a un autor se parezca a un destino, a un tiempo a través del cual el idioma se celebra festejándose a sí mismo. “Alturas de Macchu Picchu” nos adelanta de esa forma un sueño futuro de las palabras, en ellas, la lengua ya ha purgado la muerte, cumpliendo con las exequias fúnebres que sus mismas palabras le imponían. La fe en el futuro de Neruda no radica tanto en el hecho de haber sido un militante comunista, Vallejo en su tristeza también lo fue, como en el haber reconciliado el idioma con las huellas plurales de su tragedia. Por eso puede imaginar un mundo nuevo y escribir: "Sube a nacer conmigo hermano". En los últimos versos le pide a los muertos que hablen a través de su boca, que digan de nuevo, que vuelva a la palabra:

Apegadme los cuerpos como imanes.

Acudid a mis venas y a mi boca

Hablad por mis palabras y mi sangre.

Lo cierto de esos versos es que se cumplen, su condena es que permanentemente, en cada segundo de la existencia, se están cumpliendo. Neruda, al proponerse para sí el ser un intérprete, nos muestra que cada hombre al hablar no es solo uno. Que todo hombre no puede sino ser un intérprete, y no como una experiencia especial, mística o iluminada, sino como la más básica de las experiencias, y sin la cual todo aquello que insistimos en denominar lo humano se cancelaría en menos de un segundo. Una observación que se le puede hacer al trabajo de Alain Siscard en torno al yo nerudiano radica en esto. No se trata tanto de un yo ego céntrico o ego excentrado como él lo plantea, ni del enunciador epopéyico que menciona Julio Piñones Lizama, sino de que el acto mismo de hablar, cotidiano, diario, es precisamente darles una nueva oportunidad a quienes nos han precedido, a los muertos, para que vuelvan a hablar, para que se vuelvan a tomar la palabra. Mirar, sentir, oír, es siempre mirar por los ojos de los que han estado. Los Andes, una montaña cualquiera, no es sino la amontonada suma de las miradas que ya la han visto y cada cuerpo vivo al verlas es saludado nuevamente por esos ojos muertos. Eso es lo conmovedor del mundo; cada grano de polvo, cada hierba, cada estepa, es el puerto de llegada de un río de difuntos en el cual los que nos han precedido se encuentran y a quienes nosotros al oír, al ver, al hablar, en suma, al ejercer la vida, les estamos dando la oportunidad de una existencia nueva. Al final es eso lo que se entiende por una tradición y una cultura; ese torrente de seres que estuvieron, que miraron y que sumando pupilas sobre pupilas, miradas sobre miradas, con sus violencias, espejismos y temores, han levantado solo para que nosotros las veamos, las entregadas formas de las montañas. Las formas de una naturaleza impresionante y sinfónica, pero que es sobre todo un inmenso recordatorio, donde los frisos de cada nevado, de cada llanura y costa, nos recuerdan una a una las incontables muertes que contienen. En cada palabra, que nos decimos, en cada mirada, en cada poema o línea que podamos escribir, está o no que aquellos que nos antecedieron tengan la oportunidad de una vida nueva. Es creo, la única dimensión moral que tiene sentido y de allí la apelación de los dos versos finales de las Alturas. La escritura, sea cual sea su 
tema, su motivo o su forma, es siempre entregarle al pasado un relato redimido, y la grandeza de "Alturas de Macchu Picchu” radica en gran parte en habérnoslo mostrado. Porque si aquello que el cristianismo ha denominado la resurrección aún nos está diciendo algo, es que ella no va a ocurrir al final de los tiempos porque ocurre en cada instante de nuestras vidas. Absolutamente todo ser humano no es sino el territorio de esa resurrección permanente. El Canto General es la máxima representación de eso, mejor dicho: es exactamente eso. Pablo Neruda al escribirlo no sabía que ese libro iba a ser la prueba de que las comunidades que a través de él lo escribieron y que allí se mencionan, debían atravesar todavía la "muerte general” y sobrevivir a ella. Desde los albores de la conquista, un soldado español nos hablaba sin saberlo de los desaparecidos modernos. Esas obras no están en el pasado.

Porque en rigor, ninguna está en el pasado. Cuando leemos un libro lo ponemos delante de nuestros ojos, no detrás, y eso es, ni más ni menos, que abrirnos a una dimensión de nuestro porvenir. Leer es así una forma de futuro y para la poesía el futuro también puede ser un suceso que ocurrió hace quinientos o mil años. Hechos vastos y terribles como las guerras, las dictaduras o el holocausto tienen para el poema la misma intensidad que puede tener una imagen de un caldillo de congrio, una mariposa zigzagueante entre las flores o el brillo de una lágrima que alcanza apenas a asomarse desde unos ojos cerrados. Para el poema, como para una vida, el fin de la humanidad o un nuevo nacimiento ya pueden haber ocurrido o están ocurriendo permanentemente. El combate de Ardheya y Arjuna del Mahabaratta, la destrucción de Troya, la construcción de la muralla china, la conquista de América, el abandono de la ciudadela incásica de Macchu Picchu, suceden permanentemente en nuestra existencia y en la poesía.

Palabras clave: Neruda, poesía, estudios, lenguaje, español.

KEY WORDS: Neruda, poetry, studies, language, spanish. 